\title{
A proposed performance-based highway design process: incorporating safety considerations
}

\author{
C. E. Carrigan \& M. H. Ray \\ RoadSafe LLC, USA
}

\begin{abstract}
The current highway design practice in the United States allows for flexibility in application of geometric design principals, however, lacks a formal methodology resulting in varying degrees of application by region, agency and individual. While the consequences of design flexibility (i.e., construction cost, capacity, highway safety, etc.) are recognized, an improved method of quantifying and comparing the consequences of design decisions is needed to allow for more informed decision making. This paper proposes a performance-based design process which can be implemented using the tools, research and published design documentation that exists within the highway engineering community. This process capitalizes on existing workflow for increase acceptance among professionals. Implementation will lead to an improved understanding of the impacts to safety and other outcomes caused by relaxing design standards to accommodate existing ROW, environmental constraints, and other items traditionally viewed as constraints.

It is the objective of this paper to present a proposed performance-based highway design process demonstrated using highway safety as the measurable outcome. The proposed process can be extended to include other highway engineering performance outcomes such as vehicle capacity but this paper focuses solely on the safety performance of highway alternatives.

Keywords: highway safety, performance-based design, cost/benefit analysis.
\end{abstract}

\section{Introduction}

The current highway design practice allows for flexibility in the application of design principals and is long-established and rooted in the highway design community. The practice itself, however, lacks a formal methodology resulting 
in varying degrees of application of engineering principals by region, agency and individual. The flexibility that currently exists in Highway Engineering must remain, but an improved understanding of the consequences (i.e., construction cost, capacity, highway safety, etc.) of this flexibility is needed. This improved understanding can be accomplished through establishing a highway design process which is performance-based rather than prescriptive (e.g., warrants). Any changes to the current design process, however, must incorporate the long and rich history of highway design and the extensive existing body of knowledge and research on highway characteristics.

In addition to the many established safety design standards used by highway planners and designers, there are also many statistical models which have been developed to predict where crashes may occur along the road and the roadside. These mathematical models often consider the vertical and or horizontal alignment of the highway, the placement of roadside objects, the speed of the traffic, and many other factors in relation to each other. The use of these models during planning and design in conjunction with established design standards will bring the issue of maximizing highway safety to the forefront of the highway design process. An informed discussion of the cost of changes to an alignment can be assessed over the design life of a highway with the economic impacts of safety also a factor in the analysis. These models, however, are not easy to integrate into the typical highway design process which uses computer software like InRoads and Civil3D to generate detailed designs.

It is the objective of this paper to present a proposed performance-based highway design process which capitalizes on the existing body of knowledge, available CAD tools and analytical tools. The proposed performance-based process is demonstrated using improvements in highway safety measured in dollars, as the measurable outcome. The process can be extended to include other highway engineering performance outcomes such as vehicle capacity but this paper focuses solely on the safety performance of highway alternatives.

\section{Current design practice}

The current highway design practice used in the United States is based on a series of design manuals which rely on a progression of decisions about the intended use of the facility. The expected volume of traffic, the speed the traffic should be able to travel and the expected level of service are process inputs. Based on these initial assumptions, the designer makes another set of design decisions regarding the number of lanes and the sight distances to be provided, which are supported by published policies and manuals such as A Policy on Geometric Design of Highway and Street [1] (Green Book) and the Roadside Design Guide [2] (RDG), published by AASHTO; the Manual of Uniform Traffic Control Devices [3] (MUTCD), published by the U.S. Federal Highway Administration (FHWA); and the Highway Capacity Manual [4] (HCM2000), published by the Transportation Research Board (TRB). Each State generally supplements these publications with its own Highway Design Manual. AASHTO's most recent publication, the Highway Safety Manual [5] (HSM), is 
intended as a guide to assess the safety implications of design decisions. Designers also rely on a variety of software tools to support their design tasks. For example, the Highway Capacity Manual is supported by the HCM2000 software (HCS2000); the RDG cost-effectiveness analysis calculations are supported by the Roadside Safety Analysis Program (RSAP); and the Interactive Highway Safety Design Model Crash Prediction Module (IHSDM CPM) implements portions of the HSM to predict crash frequency for highway and intersection segments.

The warrants and guidelines used during a typical highway design are longestablished and rooted in the design community as the basis for every design. The existing highway design process, however, is not a formal one nor is it documented in literature. There is a surprising lack of guidance about the process one would follow to complete a design using the policy set forth in the "Green Book." There are, of course, many factors influencing any design, but every design follows the same general steps. These steps should be outlined in the nationwide policy on geometric design of highways. The existing process is typically handed down from generation to generation of highway designers with knowledge accumulated from field and design experience.

Application of the existing warrants and established guidelines varies by State and within States. In some States where tort liability is a greater concern, decisions to upgrade or not upgrade geometric features of a facility may be made on the basis of whether or not all of the warrants can be fulfilled. In other situations, decisions of geometrics might be made based on concerns about available right-of-way and the ability to relocate certain types of owners, environmental regulations, or impacts to such things as public park lands or historic landmarks. There is a good deal of flexibility in the existing design process which allows the designer to accommodate many obstacles during design, but accommodating all of these obstacles comes at a cost and that cost is not assessed explicitly during design.

The current process, using the guidelines discussed above and the software tools available, generally follows the following steps:

0. Pre-design preparation: Collect necessary field data.

1. Step 1: Determine if the existing number of lanes is sufficient or additional lanes are necessary to accommodate future traffic volumes.

2. Step 2: Determine the functional classification of the road and the corresponding design criteria.

3. Step 3: Simultaneously design and draft the horizontal alignment electronically in a CAD program overlaid on the electronic field survey data, using the established horizontal alignment criteria.

4. Step 4: Simultaneously design and draft the proposed ground profile using the previously established vertical alignment criteria.

5. Step 5: Draft a typical cross-section using the proposed number of lanes and produce cross-sections of the corridor. 
6. Step 6: Edit these cross-sections, horizontal and vertical alignments as needed to minimize impacts to right-of-way (ROW) and environmentally sensitive areas.

7. Step 7: Produce a Construction Cost Estimate and submit preliminary plans and estimate for review, sometimes called the $80 \%$ review

8. Step 8: Address reviewing agency concerns with the geometric design. Produce a pavement stripping and signing plan, construction specifications, more detailed construction plans and cost estimate. Submit Final plan set for review, often called the $100 \%$ review.

9. Step 9: Address reviewing agency concerns with construction documents and produce final Plans, Specifications, and Estimate (PS\&E).

10. Step 10: Project is Bid and Constructed. Areas of safety concern are often identified after the project is constructed and opened to traffic.

\section{Proposed design practice}

The current highway engineering workflow, discussed previously, lacks formal documentation, but allows for a great deal of flexibility. This flexibility must remain, but an improved understanding of the consequences (i.e., construction cost, capacity, highway safety, etc.) is needed. This improved understanding can be accomplished through establishing a highway design process which is performance-based rather than prescriptive (e.g., warrants).

A generic design process is shown in Figure 1. This process could represent the design process for a variety of items ranging from the design of a chair to the design of a tall building. Adapting this general process and merging it with the existing workflow, summarized in Figure 2, will allow for the introduction of performance-based design while maintaining the knowledge which has accumulated in this history-rich field.

Today most highway engineers designing use CAD software tools. These tools have coded workflows which support the existing typical highway design workflow. Figure 3 depicts the Civil 3D workflow for creating a highway corridor model. There are obvious similarities between the workflows shown in Figures 2 and 3. Successfully implementing a performance-based highway design process requires consideration of Figure 3 as well. Much of the typical design practice outlined in Figure 1 is touched on in Figures 2 and 3, however, Synthesis and Analysis are currently largely missing in highway engineering.

The proposed performance-based design process capitalizes on the extensive use by practitioners of CAD-based design suites such as Autodesk Civil 3D (Civil 3D) and Bentley Inroads within the highway engineering field.

A review of all three figures reveals that successfully moving highway engineering toward performance-based design requires more synthesis and analysis steps. Figures 4-6 provide the proposed performance-based highway design process. 


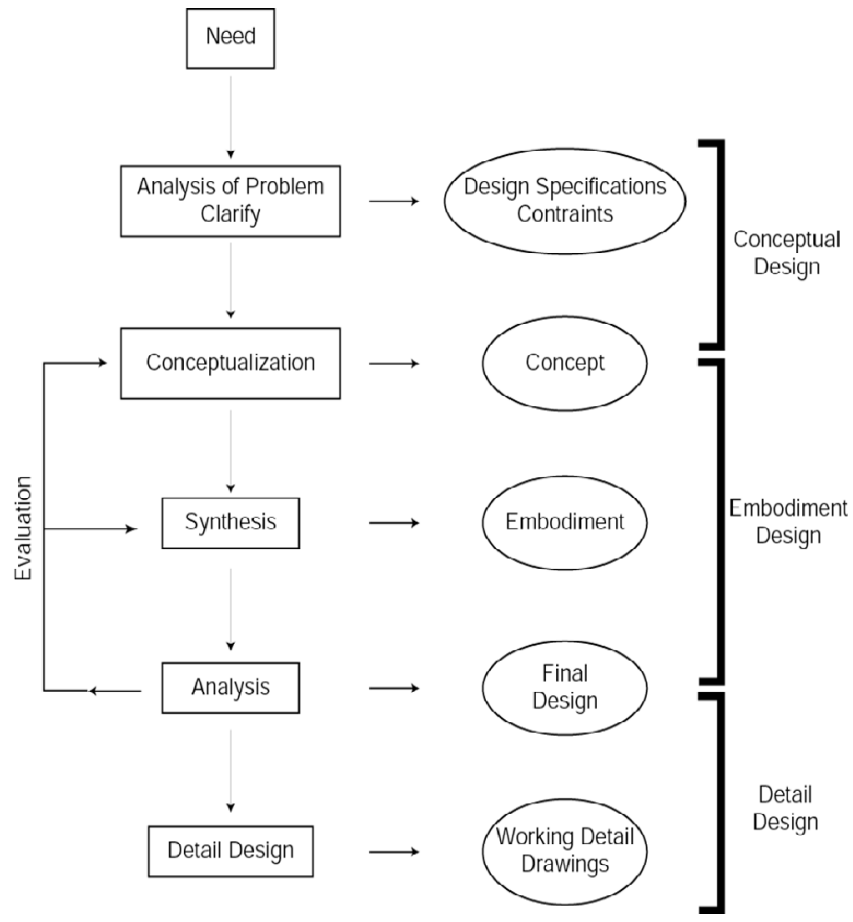

Figure 1: Typical design process [6].

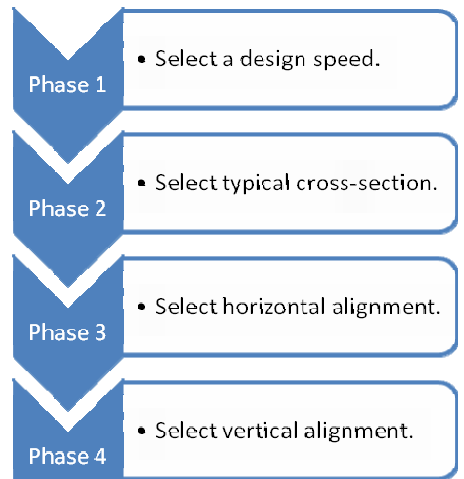

Figure 2: Existing highway design workflow [6].

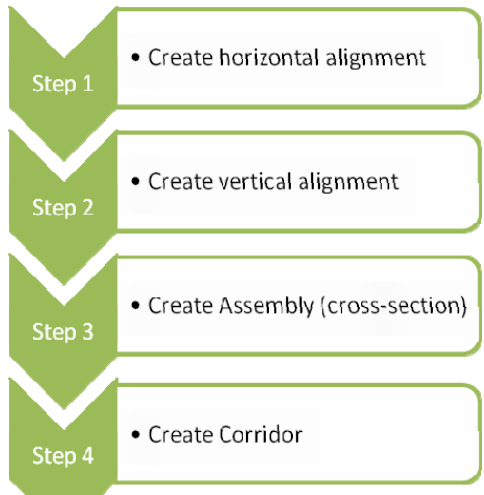

Figure 3: Civil 3D workflow for creating a highway model [6]. 
Establish Need (i.e., over capacity and/or safety improvement, maintenance, etc.)

Planning Level Analysis of problem (using HSM, HCM, etc. to determine if adding a lane, shoulders, rumble strips, etc. will alleviate problem)
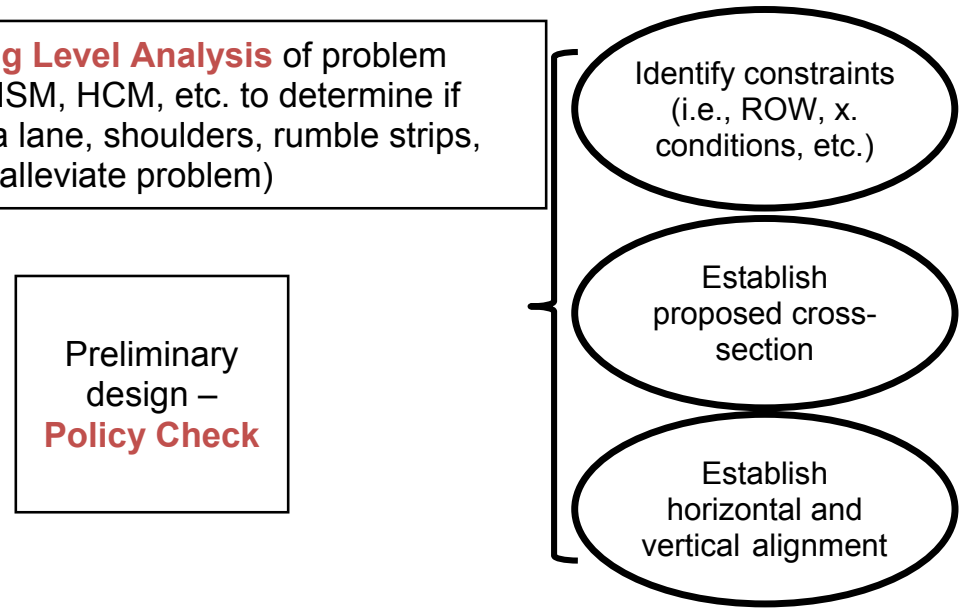

Figure 4: Proposed planning and preliminary phases.

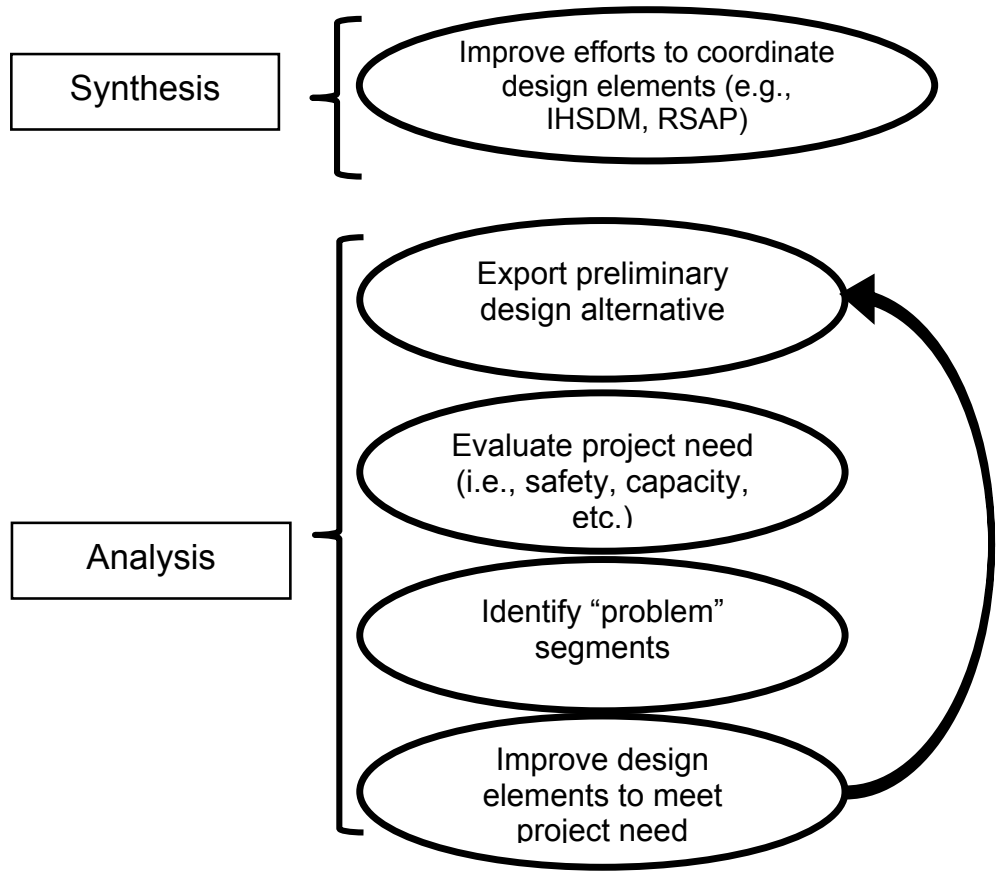

Figure 5: Proposed synthesis and analysis phases. 
Final design

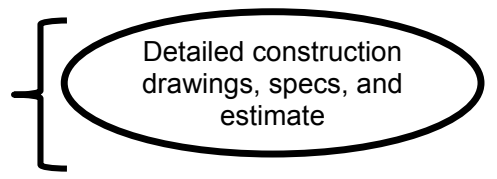

Figure 6: $\quad$ Proposed final design phase.

The implementation of this process is discussed in more detail below. Reference will be made to the "Steps" which are currently part of the existing highway design workflow and are proposed to be integrated into the proposed process. These existing "Steps" were discussed and outlined above.

\subsection{Establish need}

Prior to commencing a project, a formal documentation step should be undertaken to establish the need for the project. For example:

- Is the subject road experiencing an unacceptable number of crashes; are there particular types of problem crashes?

- Is the subject road operating over capacity and experiencing significant delays? (similar to existing Step one)

- Is the subject road in need of pavement maintenance to improve the ride quality?

It is possible that the highway has more than one need for improvement. Conducting this step will allow for all project participants to agree on the goals for the project and for planners and engineers to determine if the project's goals have been met during the analysis phase. Failure to conduct this step could results in losing sight of the project's original purpose and "scope creep."

\subsection{Planning level analysis}

After determining the need for a project, the ability to meet the established need with highway engineering should be evaluated at the planning level. Successful highways depend on the interaction of the highway design, the vehicles, and human beings. This planning level analysis should be conducted to determine which highway engineering principals will improve the highway the most for the smallest investment. Specific, detailed analysis should not be conducted at this level. One should focus on the comparison of design concepts which can be considered with minimum field data collection. One should not design specifics such as each driveway, intersection grading alternatives, longitudinal barrier alternatives, impact attenuators, etc.

Using available GIS information and historic traffic volumes, one can determine if adding a lane will significantly reduce congestion, widening the shoulders and installing rumble strips will improve safety, and/or resurfacing the road will improve the ride quality. Each one of these improvement alternatives has a direct cost for the improvement, indirect costs for items such as the environmental impacts and costs (benefits) associated with the improvements. 
Conducting a cost/benefit analysis of each alternative will allow the engineer to determine which alternative to pursue.

Sufficient research does not exist to quantify the interaction of each of these improvements on the other, however, one can be reasonably sure that resurfacing the road and/or widening the shoulders would improve capacity and also increase speeds. When such research becomes available, this step will become increasingly more important.

\subsection{Preliminary design: policy check and corridor model assembly}

After one determines through cost/benefit analysis which alternative should be designed, the preliminary design of the alternatives should follow. Preliminary design includes several parts which progress simultaneously at times:

- Identify Constraints,

- Establish Proposed Cross-section and

- Establish Proposed Horizontal and Vertical Alignments.

\subsubsection{Identify constraints}

Currently, highway engineers gather field data, including field survey data and traffic volumes, at the onset of design. This should continue and the field data should be included in the project's electronic model. At this time increased efforts should be made to identify and document constraints which may hinder the implementation of the selected alternative. A detailed review of field data may reveal areas of narrow rights-of-way; challenging side slopes or underground utilities which were not initially evident from field visits or planning-level study. These constraints which may impact the project's budget and/or ability to progress should be noted, but the design should be modeled using the prescribed warrants in the Green Book [1] and RDG [2]. Changes to the design to accommodate the constraints will be assessed later in this design process.

\subsubsection{Established proposed cross-section}

Using the capacity analysis performed during the Planning Level Analysis with the Highway Capacity Manual (HCM) [4] to establish the number of lanes, the Green Book [1] warrants for lane and shoulder width, and the Roadside Design Guide (RDG) [2] to establish clear zones, the highway engineer should determine the desirable proposed cross-section. This step represents portions of steps two and five of the existing highway design workflow.

It is plausible and often warranted to have more than one cross-section throughout the length of a project. In this case, all warranted cross-sections, the start and end stations, and transitions should be documented and modeled. It is entirely possible and often probable that the desirable cross-section cannot be accommodated without impacts to the identified constraints (i.e., the crosssection may not fit within the available right-of-way), however, the cross-section should be established and modeled in CAD using the prescribed warrants. A design level "analysis" of alternatives follows in the coming steps and will assess 
the impacts of cost, safety and other measurable outcomes which result due to modifications to the cross-section. Alterations to the cross-section to avoid impacts should not be made until the "analysis" phase.

\subsubsection{Establish proposed horizontal and vertical alignments}

Using the Green Book [1] warrants for horizontal and vertical alignments previously discussed, the highway engineer should determine the desirable alignments. This step represents portions of steps two, three, and four of the existing highway design workflow.

Again, it is possible that accommodating the alignments prescribed by the Green Book will impact the identified constraints or incur costs beyond those budgeted, however, these alignments should be initially included in the CAD model with any adjustments to the alignments assessed during the "analysis" phase and compared to the Green Book design at that time.

\subsection{Synthesis: improve efforts to coordinate design elements and reduce speed inconstancies}

The existing design workflow lacks emphasis on coordinating design elements, however, research indicates that increased attention to this area will improve visibility, highway safety and reduce speed inconsistencies [7-9]. CAD-based highway design software suites such as Civil 3D contain tools which aid the engineer in conducting this step manually. Coordinating the start and end of horizontal and vertical curves allows for improved visual appearance of highway elements and reduces possible sight obstructions of highway elements caused by the highway itself.

The Green Book states "the alignment is comprised of a variety of elements joined together to create a facility that serves the traffic in a safe and efficient manner, consistent with the facility's intended function. Each element should complement others to produce a consistent, safe, and efficient design" [1]. There are no warrants provided within the text to ensure a coordinated design has been provided, however, research has been conducted and yielded models which can be used to predict the eighty-fifth percentile speed based on geometric features [7] and the suggested allowable variation from one segment to the next [7].

The Interactive Highway Safety Design Model (IHSDM) has five modules, including the Design Consistency Module, which helps diagnose safety concerns at horizontal curves. Crashes on two-lane rural highways are overrepresented at horizontal curves, a problem which has been partially attributed to speed inconsistencies. The design consistency module estimates 85 th percentile vehicle speeds at each point along a roadway. The speed-profile model combines estimated 85th percentile speeds on horizontal and vertical curves, desired speeds on long tangents, acceleration and deceleration rates at points of curvature and tangency, and a model for estimating speeds on vertical grades [8].

Increased effort should be given to using the tools available to highway engineers to coordinate design elements and evaluate geometric influences on speed (e.g., the IHSDM). Additional development of this research should focus on integrating the tools available through the IHSDM into CAD software to 
facilitate an interactive design environment. Currently, designers must export CAD files to LandXML and import the LandXML file into the IHSDM.

\subsection{Analysis}

Step six and seven of the existing highway design process work to evaluate highway designs to minimize impacts, but fail to quantify design decisions. These existing steps are not formal and rely heavily on engineering judgment. Three different engineers could design the same road to the same standards and the result could be three different designs. Highway engineering and design has a good deal of flexibility, but highway engineers lack the analytical resources necessary to assess the impacts of exploiting that flexibility. For example, a road with two twelve foot lanes and three foot shoulders could have any of the following roadside treatments:

1. Flat ground with twenty-four foot clear zones,

2. 4:1 side slopes with twenty-four foot clear zones or

3. 3:1 side slopes with guard-rail to protect the errant vehicles from the side slopes.

While each one of these alternatives may meet the suggested warrant, the cost for constructing and maintaining these alternatives is different and the potential for crashes is different. No one alternative is the correct choice for every twolane road and each road should be analyzed individually to find the most costbeneficial safety treatment for the particular project constraints.

At this point in the proposed performance-based highway design process, the engineer has a corridor (horizontal and vertical alignments and cross-sections) for the roadway which meets Green Book and RDG warrants. Constraints have been identified and the engineer has a good understanding of where the corridor may need to change to avoid the identified constraints. While maintaining an electronic copy of the CAD corridor model which is modeled to the published design standards (Alternative one), the engineer should modify the corridor design to accommodate the constraints. More than one alternative or combination of alternatives may be developed (Alternative two, three, etc.). These alternatives may include changes to roadside slopes, changes to lane width, changes to the horizontal or vertical alignment or other highway design alteration. Each of these alternatives should be compared to Alternative zero using a Cost/Benefit analysis to determine the potential impact to safety, project cost, and other stated outcomes over the life cycle of the project that any one of these changes may have.

Recall Figure 5. This step should be persistent as changes are made to the corridor, until a satisfactory design is achieved. As research continues, software which supplements existing CAD-based highway design packages should be developed to support this step.

The engineer should evaluate the potential for crashes and other stated outcomes, considering the combined effect of the corridor geometrics, for the existing conditions (Alternative Zero) and the alternative which meets design 
guidelines (Alternative One). Alternative zero and one can then be compared to any changes (Alternatives Two, Three, etc.). Upon selecting a preferred alternative, the established project need should be revisited to determine if the preferred alternative meets the project need. Provided the project need is met, the design can proceed to the next step. In the event the project need is not met, analysis should continue until the project need is met.

A report should be prepared documenting the project constraints, existing conditions (Alternative zero), the alternative which meets design guidelines (Alternative One), other alternatives considered, the construction cost, maintenance and crash costs of each alternative, the expected crashes of each alternative and the resulting cost-benefit ratios. This report and accompanying preliminary design plans should be submitted to the reviewing agency for comments. The reviewing agency should focus on whether the alternative meets the project's stated need; concurrence with the identified constraints and identifying any other constraints; and the analysis of the costs and project safety. Evaluation for agreement with governing policy becomes less important than in the existing highway design workflow, as the engineer's report documents Alternative One and its impacts, the deviations from Alternative One have been stated and the safety impacts have been quantified.

\subsection{Final design}

Following the receipt of funding-agency comments, the selected design alternative proceeds to the Final Design phase. Final Design is similar to Step eight of the existing highway design process. After addressing any review comments and prior to construction document preparation, a public hearing should be held to allow for public review and comment.

Following a public hearing, a detailed design and construction documents are prepared and submitted for review. These plans are prepared as similar to Step 8 of the existing highway design workflow. The construction documents are submitted once again for review. At this point, the construction documents are reviewed for oversights or lack of coordination in the documents which could lead to cost overruns or miscommunication of design intent. The geometric design is not reviewed at this time.

Next, the project will precede to Steps nine and ten as outlined in the existing highway design workflow. These steps include bidding the project and constructing the project.

\section{Conclusions}

The proposed performance-based design process can be easily implemented using the tools, research and published design documentation which already exists within the highway engineering community. This process will reduce workload for reviewing agencies and coordinate efforts throughout different regions. Efforts will be focused on performance outcomes such as improving highway safety and reducing highway related fatalities rather than policies and 
warrants. This process capitalizes on existing workflow and tools for increase receivership among highway designers and can be expanded to include a full array of performance-based highway engineering. Implementation will lead to an improved understanding of the impacts to safety and other outcomes caused by relaxing design standards to accommodate existing ROW, environmental constraints, and other items traditionally viewed as constraints. This improved understanding will lead to more informed decision making.

\section{References}

[1] "A Policy on Geometric Design of Highways and Streets", $5^{\text {th }}$ edition", American Association of State Highway and Transportation Officials (AASHTO), Washington D.C., 2001.

[2] Roadside Design Guide, 3rd edition with 2006 Chapter 6 Update, American Association of State Highway \& Transportation Officials, Washington, D.C.

[3] Manual on Uniform Traffic Control Devices, 2003, U.S. Department of Transportation-Federal Highway Administration, Washington, DC.

[4] Highway Capacity Manual (HCM 2000), 2000 edition, Transportation Research Board-National Research Council, Washington, DC.

[5] "The Draft Highway Safety Manual," American Association of State Highway and Transportation Officials, Washington, D.C., current as of April 6, 2009.

[6] Conron, C.E., Bergendahl, J.A., Bringing Graphics and Design to First Year Engineering Students, American Society for Engineering Education, Engineering Design Graphics Division, 63rd Annual Midyear Meeting Conference Proceedings, January 2009

[7] Lamm, R., Psarianos, B., Mailaender, T., Highway Design and Traffic Safety Engineering Handbook, McGraw-Hill, New York, 1999

[8] Krammes, R.A., Hayden, C., "Making Two-Lane Roads Safer", Public Roads, US Department of Transportation, Volume 66, No 4, January/February 2003 